\title{
Problems and Countermeasures in the Implementation of Sustainable Development Strategy for Environmental Protection Enterprises in the New Period
}

\author{
Yan Gu, Qingjun Meng \\ Business School of Hohai University, Nanjing, China \\ Email: 1025380489@qq.com
}

Received 4 May 2016; accepted 23 May 2016; published 26 May 2016

Copyright (C) 2016 by authors and Scientific Research Publishing Inc.

This work is licensed under the Creative Commons Attribution International License (CC BY). http://creativecommons.org/licenses/by/4.0/

(c) (i) Open Access

\begin{abstract}
Our country has put forward a new orientation of green development and has supported the development of environmental protection enterprises. With the development of social economy and the improvement of people's living standard, environmental protection enterprises are meeting new opportunities. However, there are still many problems in the development of environmental protection enterprises. For example, policy mechanism and legal system are not perfect, environmental protection enterprises are lack of innovation abilities and financing is difficult. A series of effective measures are needed, such as to sound legal system and policy mechanism, strengthen supervision. Environmental protection enterprises should strive to improve competitiveness and enhance cooperation with scientific research institutes, financial and other organizations. Only in this way, environmental protection enterprises are able to implement sustainable development strategy in the new period.
\end{abstract}

\section{Keywords}

The New Period, Environmental Protection Enterprise, Sustainable Development, Innovation, Competitiveness

\section{Introduction}

After more than 20 years' development, environmental protection enterprises in China have formed a diversified structure covering environmental consulting, environmental protection equipment, engineering design, facility operation and maintenance in key areas, such as water, air, solid waste disposal and environmental service. Main listed companies are KaiDi Electric Power (000939), SanJu Environmental Protection (300072), BiShuiYuan 
(300070) and so on.

According to National Development and Reform Commission, by the end of 2015, output value of the environmental protection industry reached 4.5 trillion yuan. Policy support has been increased, such as "air pollution prevention action plan", "water pollution prevention action plan", "soil environmental protection and pollution control action plan", this leads the environmental industry to marketization. But as a strategic emerging industry, the environmental protection industry is still in the initial stage of development, there is a big gap to become a pillar industry of the national economy. As an important part of environmental protection industry, in the face of the great opportunities of the new period, environmental protection enterprises shall improve their awareness of environmental protection, improve environmental protection facilities to reduce pollutant emissions, continuously improve production process, pursue "green" production and make contributions to economic development.

\section{Relevant Studies}

Mao Rubai (2014) put forward that environmental protection enterprises in the new period are facing some problems. First is lack of supervision; second, the responsibility of the enterprise is not in place, enterprises should put pollution control, pollution reduction, development of new economic as their responsibility; Third, the innovation of system, mechanism and technology is obviously insufficient. In the new situation, we should further explore how to promote the sustainable development of environmental protection enterprises through institutional, mechanism and technological innovation. Chen Jining (2015) pointed out that on general consideration, environmental protection is currently in a period of strategic opportunities. At the same time, we should also notice that environmental protection enterprises are still in a critical period of heavy load and facing many new difficulties and challenges [1]. This view has substantive significance to the necessity of implementing sustainable development strategy.

The environmental protection enterprises in our country are in the initial stage where there are many kinds of research on environmental protection enterprises. Guangri, Li believes that environmental protection enterprise in our country is facing many problems such as lack of competitiveness, low technology content of products, lack of policy guidance and related support and so on. He also put forward targeted solutions [2]. Zhu Jingran thinks from the perspective of ownership structure and environmental protection industry listing Corporation. She analyzed the relationship between investment and financing and sustainable development strategy of the company [3]. Wu Qiusheng holds that we should perfect the sustainable development of environmental protection enterprises through government's call, technological innovation and supervision mechanism [4]. These studies tend to focus on responsibility or technology. If we can take social public opinion, environmental input and output and financing issues into account, we will be able to carry out a more comprehensive analysis.

\section{Main Problems Existing in the Development of Environmental Protection Enterprises in China}

\subsection{Policy Mechanism and Legal System Are Not Perfect; Supervision Is Lacked}

Policy and related laws of environmental protection enterprises are an important guarantee for the sustainable development. The new environmental protection law revised on January 1, 2015 and "air pollution prevention action plan", "water pollution prevention action plan", "soil environmental protection and pollution control action plan" have made mandatory provisions for fulfilling the obligation and social responsibility in the development of environmental protection enterprises. But the policy system is not sound. First, industrial policy and technology policy is not perfect and unified specification is lacked. The reform of prices of resource products and environmental protection fee policy has not yet in place. These have resulted in lack of strength in macroeconomic regulation and control and cannot adapt to the development of marketing economy. Second, fiscal and financial policy remains to be further perfect, enterprises have difficulties in financing and producer responsibility system has not yet been established.

\subsection{Core Competitiveness of Environmental Protection Enterprises Is Low}

\subsubsection{Small and Medium-Sized Environmental Protection Enterprises Are Numerous But the Management Level Is Generally Low}

According to the survey of the Ministry of Environmental Protection, small and medium-sized enterprises ac- 
counted for $90 \%$ of all the environmental protection enterprises in our country. The management level of small and medium-sized enterprises is low. They have difficulties in financing, so they are lack of capital and R\&D investment is very little. Besides, they are lack of innovation ability, production process is relatively backward. Although the number of enterprises is large, there is still a relatively long way to meet the need of current environmental protection.

\subsubsection{Science and Technology Content in Products of Environmental Protection Enterprises Is Low and They Are Lack of Innovation Ability}

Environmental original technology in China is less, core technology is lacked, study quality needs to be improved. Overall quality of invention patent technology is not high, core patent technologies are lacked. Colleges and research institutes are still the subjects of environmental technology research and development, innovation ability of enterprises is obviously insufficient, enterprises' R\&D strength do not have international competitiveness, problems between development and transformation are serious; core technologies and products supporting the improvement of environmental quality are lacked.

\subsubsection{Financing Channel of Environmental Protection Is Single and They Are Generally Lacked of Financial Support}

Because the environmental protection project has the characteristics of long investment and low income, the financing sources have been mainly based on finance. The majority of private enterprises in the environmental protection industry can only get limited capital investment without government policy support. Under the background that financing requirements of the environment sector continue to expand and the financial costs continue to increase, intense market competition may directly affect the operating income and net profit of a few companies. Besides, because the project is still in the run, enterprises in the new period would not reach the expectation.

\subsection{Public Opinion Support Is Not Enough}

In recent years, with words such as "PM2.5" and "smog" well-known, the public's environmental protection consciousness has gradually enhanced. More and more people begin to pay close attention to and promote the development of the cause of environmental protection. But this is not a significant and effective pressure on pollution behavior and pollution source control.

According to "2015 Chinese city residents' environmental awareness investigation” released by public opinion research center of Shanghai Jiaotong University, nearly half of the residents' cognition of environmental protection is low, their environmental consciousness is weak and their behavior to support environmental protection is not enough [5].

\subsection{Development of Environmental Protection Non-Governmental Organizations Is Limited}

China Environmental Protection Association (CEPA), China Environmental Protection Industry Association and others have built an important bridge and channel to enhance the communication between the government and the public. However, they also face many problems which restrict their healthy and orderly development. And this must be harmful to the sustainable development of enterprises. First is lack of funding: the government provides little support for these organizations and there exists lack of necessary fiscal and taxation that encourages its development. Second, ability and approach to participating in making policy and social supervision are restricted, so the efficiency is low. Third, the ngos established by the government departments are too dependent on the government that they seldom communicate with the public, so they are lack of mass base [6].

\section{Countermeasures of Sustainable Development Strategy of Environmental Protection Enterprises}

\subsection{Sound Policy Mechanism and Legal System, Strengthen Supervision and Punishment}

State Environmental Protection Departments shall perform their duties and step up efforts to promote the development of environmental protection enterprises. The first is to improve the rule of law, mainly around the im- 
plementation of environmental laws, and comprehensively promote the construction of environmental protection laws and regulations and standard system, give full play to the leading role of environmental economic policies. Such as the establishment of environmental protection special fund which can alleviate the shortage of funds for small and medium-sized environmental protection enterprises, etc. Tax policy can also be used which adopts the policy of tax reduction and exemption to strengthen support for environmental protection enterprises up to standard. The new environmental protection law revised on January 1, 2015 opened a new chapter for the cause of China's environmental protection. Two laws, three action plan and its supporting measures has perfect the legal system of China's environmental protection policy. It also leads the escort and target for the development of environmental protection enterprises.

The second is to strengthen management, mainly around the three strategies related to prevention and control of the atmosphere, water and soil pollution. Strengthen environmental management and supervision of law enforcement, turn the requirements of pollution control effectively into the market demand in development of environmental protection enterprises, and then promote industrial application of major environmental protection technology, equipment and products. The last is to transform function mainly around and decentralization, continue to promote administrative examination and approval system reform of environmental protection, improve the efficiency of examination and approval, broaden the channels for the supply of government environmental services, promote the governments at all levels to buy environmental service from social forces.

\subsection{Enhance the Core Competitiveness of Environmental Protection Enterprises to Fight for Living Space}

\subsubsection{Improve the Management Level of Enterprises, Implement the "Talent" Strategy}

Enterprises should strengthen the investment of talents, cultivate high-quality environmental protection personnel. For example, set up professional training institutions to develop three forms of talent training project including compound talents, technical talents and management trainee. Cultivate a strong scientific and technological team by inviting domestic and foreign well-known experts, holding regularly technology BBS, establishing production-study-research cooperation relationships with universities, offering joint training of personnel and other forms [7]. Strengthen financial management, put the limited funds into key positions, key technologies and equipment.

\subsubsection{Put Great Efforts to Strengthen Innovation Ability, Combine Production, Study and Research} Our government should not only maximize the promotion and application of existing environmental technology, but also invest heavily in research and development. So that it can provide advanced technology source of environmental protection enterprises. Environmental protection enterprises should be based on their existing technology and market, constantly strengthen technological innovation and market investment, and form a particular, fine, pointed vertical company in a specific field.

Enterprises shall carry out technology research and development cooperation with peer companies, environmental science research institutes, the university scientific research platforms and international environmental organizations in the common environmental or economic interests. In this way, they will have access to broader capital, talents, research experience and can also combine the power of the parties to share risks.

\subsubsection{Expand the Channels of Low Cost Financing for Enterprises}

Enterprises should establish diversified financing channels. The government can encourage foreign enterprises, local governments, private enterprises to enter the environmental protection enterprises so that financing channels can be expanded with the diversification of investment subjects; establish special fund for environmental protection enterprises to support their development; allow environmental protection enterprises listing and issuing securities to solve the financing difficulties; increase financial assistance free of charge for private environmental protection enterprises, such as discount loans and financial guarantee, etc.

\subsection{Support of Public Opinion Can Promote the Development of Environmental Protection Enterprises}

According to "the individual citizen action investigation" carried by China Environmental Network in 2014, relatively more people think they can promote environmental governance in the field of individual action and green 
consumption. Full participation of the public and the press can ensure that the implementation of the management of sustainable consumption is open and transparent, which is a powerful supplement to government supervision. Therefore, residents' positive role can form a pressure on the behavior of environmental pollution. At the same time, the government should strengthen the construction of related systems to protect rights of the residents to participate in environmental protection, such as residents' right to know the relevant issues, participate in the design and feasibility study of major projects, supervise the implementation of major projects and so on [8].

\subsection{Strengthen the Function of Non-Governmental Organizations in Environmental Protection, Improve the External Constraint System}

Environmental protection ngos have become an important force to protect the environment and promote harmony between human and nature. On one hand, the government department should increase training efforts in ngos to enhance their political sense, the level of management, business capacity and the degree of specialization. It also has to expand the channels of communication and strengthen their international communication and cooperation from home and abroad to draw lessons from experience and promote the development. On the other hand, ngos should strengthen their own functions. Firstly, they should improve internal management that everyone has to earnestly fulfill the purpose and to do things by regulations and articles of association. Secondly, organizing the work of environmental publicity and education to improve the environmental consciousness of the whole society is also important. At last, it has to carry out the supervision to make recommendations for environmental cause.

\section{Conclusion}

In the new period, China's environmental protection enterprises are in the development opportunity, but the challenges should not be ignored. In order to better adapt to the transformation and promote the development of environmental protection enterprises, cooperation and innovation by the government, environmental protection enterprises, public opinion and environmental non-governmental organizations are needed. Because development time of China's environmental protection enterprises is short compared with that of developed countries and we are lack of experience, it is necessary to strengthen cooperation and exchanges with the same industry in developed countries. In a word, with the improvement of people's living standards and scientific literacy, demand for the products and services of environmental protection is increasingly growing. Environmental protection enterprises should have the courage to bear social responsibility, enhance core competitiveness and meet market demand. Only in this way, they are able to fight for living space and eventually improve the economic benefit.

\section{References}

[1] Chen, J.N. (2015) The Environmental Protection Work Is in a Period of Strategic Opportunities. http://www.cnstock.com/v_industry/sid_rdjj/201508/3545883.htm

[2] Li, G.R. (2015) Present Situation and Development of Environmental Protection Industry in China and Its Existing Problems and Measures. Chinese New Technology and New Products, No. 19.

[3] Zhu, J.R. (2015) Research on the Relationship between Ownership Structure and Corporate Performance of China's Environmental Protection Industry Listing Corporation. Market Weekly (Theoretical Study).

[4] Wu, Q.S. and Li, J. (2016) Research on the Current Situation and Countermeasures of China's Environmental Protection Industry. Resource Conservation and Environmental Protection, No. 2.

[5] Survey on Environmental Awareness of Chinese Urban Residents in 2015 http://www.chinaenvironment.com/view/ViewNews.aspx?k=20151222100431507

[6] China Environmental Protection Association (2006) Report on China Environmental Protection Non-Governmental Organizations Development Status. Environmental Protection, No. 10.

[7] Zhang, L.L. and Lin, R.Q. (2013) Problems and Countermeasures in the Development of China's Environmental Protection Industry. Technology and Enterprise, No. 21.

[8] Ma, Y.Z. (2011) Current Problems and Countermeasures of China’s Environmental Protection Industry. Economic and Management Research, No. 3. 